\title{
UMA ANÁLISE ONTOLÓGICA SOBRE A RELAÇÃO DE UNIDADE NA CONTRADIÇÃO ENTRE PRODUÇÃO, DISTRIBUIÇÃO, TROCA E CONSUMO
}

\author{
José Pereira de Sousa Sobrinho ${ }^{1}$
}

\section{Resumo:}

A análise marxiana busca expor a lógica interna da sociedade do capital, exposição na qual os diversos momentos do desenvolvimento da sociedade burguesa são apresentados em suas particularidades. Um dos momentos da exposição dialética apresenta a unidade entre produção, distribuição, troca e consumo como uma unidade orgânica, que compõem a totalidade do processo de reprodução da sociedade burguesa. Contudo, a análise marxiana expõe que o processo de reprodução coletiva da sociedade contém em si o movimento ontológico de constituição do ser social em sua individualidade, a qual é vinculada a momento histórico específico, formando, portanto, uma individualidade capitalista.

Palavras-chave: Reprodução social, Totalidade, Ontologia.

\begin{abstract}
:
The marxian analysis seeks to expose the internal logic of the society of capital, exposure in which the diverse moments of the bourgeois society development are presented in its particularities. One of the moments towards dialectical exposition shows the unit between production, distribution, exchange and consumption as an organic unit which composes the totality of the bourgeois society reproduction process. However, the marxian analysis exposes that the society's collective reproduction process has itself the ontological constitutive movement of the social being in his individuality, which is linked to a specific historical moment, forming therefore a capitalist individuality.
\end{abstract}

Keywords: Social reproduction, Totality, Ontology.

A apreensão de Marx (1987) a respeito da natureza humana leva-o à seguinte conclusão: o homem é um ser da natureza, contudo a sua natureza é essencialmente social, assim, a produção individual ou isolada é sempre uma produção em sociedade - de onde o autor conclui que as apreensões do ser em seu suposto isolamento tão comum à filosofia de Rousseau não passam de uma apreensão da aparência do real, pois o homem mesmo isolado, efetiva seu isolamento em sociedade.

Dessa conclusão, podemos afirmar que a produção humana é sempre uma produção

\footnotetext{
${ }^{1}$ Doutorando em Educação pela Universidade Federal do Ceará (UFC), vinculado ao Eixo Filosofia, Política e Educação. Bolsista FUNCAP. E-mail: jpssobrinho@yahoo.com.br.
} 
em sociedade por meio da qual os homens em conjunto buscam meios para atender às suas necessidades coletivas. Desse movimento, estabelecem-se os diversos modelos históricos de organização da vida, desde as comunidades primitivas até a ordem burguesa, onde são originadas determinadas estruturas de reprodução social. Estrutura que pressupõe quatro fundamentos: produção, distribuição, troca e consumo, que constituem uma unidade socialmente articulada, onde cada fundamento representa uma estrutura e, em conjunto, dão forma ao processo de reprodução social em sua totalidade. A análise marxiana do processo de reprodução social segue o percurso metodológico na qual a exposição inicia-se com os diversos conceitos apreendidos do real apresentados em suas determinações gerais abstratas. Nesse primeiro momento da análise do processo de reprodução social os quatro fundamentos - produção, distribuição, troca e consumo - são expostos em seu conteúdo geral, ou seja, o filósofo alemão apresenta o seu conteúdo interno comum a todas as formas sociais. Assim, Marx

afirma

Na produção, membros da sociedade adaptam (produzem, dão forma) os
produtos da natureza em conformidade com as necessidades humanas; a
distribuição determina a proporção em que o indivíduo participa na repartição
desses produtos; a troca obtém-lhe os produtos particulares em que o indivíduo
quer converter a quota-parte que lhe é reservada pela distribuição; no consumo,
finalmente, os produtos tornam-se objetos de prazer, de apropriação individual.
A produção cria os objetos que correspondem às necessidades; a distribuição
reparte-os segundo leis sociais; a troca reparte de novo o que já tinha sido
repartido, mas segundo as necessidades individuais; no consumo, enfim, o
produto evade-se desse movimento social, torna-se diretamente objeto e
servidor da necessidade individual, que satisfaz pela fruição. A produção surge
assim como o ponto de partida, o consumo como o ponto de chegada, a
distribuição e a troca como o meio termo que, por seu lado, tem um duplo
caráter, sendo a distribuição o momento que tem por origem a sociedade e a
troca o momento que tem por origem o indivíduo. (MARX, 1983, p. 207).

Portanto, a relação entre produção, distribuição, troca e consumo é uma relação entre determinantes e determinados na qual os diversos fundamentos constituem sua particularidade em uma unidade estabelecida diante dos diversos nexos causais originados no interior das relações sociais. A tese marxiana é que o movimento interno destes fundamentos - movimento geral do processo de reprodução da vida humana pressupõe uma determinada ordem, na qual está expressa a existência de leis sociais.

Mas, a formulação expressa por Marx na citação acima apenas expõe o conteúdo superficial da relação de unidade entre os quatro fundamentos, trata-se do momento da aparência. A continuidade do método dialético de investigação efetiva-se na necessidade de isolar o fenômeno e estudar as suas diversas determinações abstratas, ao 
isolá-lo, podemos apreender o conteúdo interno da coisa. O que é efetivado na investigação da relação de unidade estabelecida entre os quatro fundamentos, unidades determinantes menores, que estão constituídas entre produção e consumo, produção e distribuição, produção e troca. O método marxiano efetiva-se na análise das múltiplas determinações que compõem o conteúdo interno da coisa.

A primeira determinação sobre a qual Marx se debruça é a relação de unidade entre produção e consumo. Sua análise se inicia sobre o fundamento mais singular e mais superficial da unidade entre consumo e produção, qual seja, o consumo na produção - o que é realizado sobre o duplo caráter do consumo. O caráter subjetivo presente "no indivíduo que desenvolve as suas faculdades ao produzir, igualmente as despende, as consome no ato da produção, [...] é um consumo de forças vitais.” (MARX, 1983, p. 208). O segundo momento é o consumo objetivo dos meios de produção empregados que se desgastam e se dissolvem, e objetivam um novo objeto.

A riqueza do conteúdo exposto por Marx (1983, p. 207) delineia a unidade entre elementos objetivos e subjetivos, no qual se efetiva numa síntese no processo de autoconstituição do novo indivíduo que surge na esfera da produção, pois "na produção o indivíduo objetiva-se e no indivíduo subjetiva-se o objeto". O novo ser social, com novas capacidades objetivadas tem as suas capacidades adquiridas, também consumidas no ato da produção. Nesse momento, Marx expõe os resultados das formulações produzidas pela economia política burguesa sobre produção e consumo de onde surgem os conceitos de consumo produtivo e produção consumidora.

Não se trata, para Marx, de expor o equívoco de tais formulações, já que os economistas clássicos estão corretos ao apresentarem a relação de unidade entre produção e consumo. Contudo, o conteúdo dessa unidade, expressa pelos economistas clássicos, expõe apenas a sua aparência, já que Ricardo e Smith apenas apreenderam a relação de unidade entre produção e consumo em seu caráter imediato. A análise marxiana denuncia os limites das formulações da economia clássica burguesa em que a apreensão da "unidade imediata, em que a produção coincide com o consumo e o consumo com a produção, deixa subsistir a dualidade intrínseca entre ambas.” (MARX, 1983, p. 209).

A análise marxiana avança sobre as formulações dos economistas burgueses ao expor que a unidade entre produção e consumo não contém apenas uma unidade imediata. A unidade imediata é suprassumida nesse momento da análise, pois no movimento da aparência para a essência a relação de unidade entre produção e consumo adquire uma

\begin{tabular}{|l|l|l|l|l|}
\hline Revista Dialectus & Ano 1 & n. 1 & Julho-Dezembro 2012 & p. 83-94 \\
\hline
\end{tabular}


nova qualidade, ao desvendar que a unidade geral entre produção e consumo não se efetiva somente de forma imediata, mas também por meio de relações intermediadas, já que

a produção é imediatamente consumo, o consumo imediatamente produção. Cada um é imediatamente o seu contrário. Mas opera-se simultaneamente um movimento intermediário entre os dois termos. A produção é a intermediária do consumo, a quem fornece os elementos materiais e que, sem ela, não teria qualquer objetivo. Por seu lado, o consumo é também o intermediário a produção, dando aos produtos o motivo que os justifica como produtos. Só no consumo o produto conhece a sua realização última [...] Sem produção não há consumo; mas sem consumo também não haveria produção, porque neste caso a produção não teria qualquer objetivo. (MARX, 1983, p. 209).

O método marxiano permite um salto qualitativo em relação à análise econômica clássica, um novo determinante é incorporado à investigação ao avançarmos da unidade imediata para a relação de unidade intermediada. O segundo caso pressupõe relações multilaterais de determinação, que desvenda que o consumo produz a produção, assim como a produção produz o consumo. No desenvolvimento da análise do real, Marx (1983, p. 209-210) acaba por demonstrar que o consumo produz duplamente a

produção:

$1^{\circ}$. Somente pelo consumo o produto se torna realmente produto [...] Apenas o consumo, ao absorver o produto, lhe dá o retoque final (finish stroke); porque produção não se desencadeou enquanto a atividade objetivada, mas como mero objeto para o sujeito ativo [o consumo produz a produção]. $2^{\circ}$, O consumo cria a necessidade de uma nova produção, por conseguinte a razão prévia. $O$ consumo cria o móbil da produção; cria também o objeto que, atuando sobre a produção, lhe determina a finalidade. Se é evidente que a produção oferece, na sua forma material, o objeto do consumo, não menos evidente que o consumo supõe idealmente o objeto da produção, na forma de imagem interior, de necessidade, de móbil, e fim. Cria os objetos da produção sob uma forma ainda subjetiva. Sem necessidade não há produção. Ora, o consumo reproduz a necessidade.

Da análise de Marx (1983) podemos compreender que a relação entre produção e consumo é intermediada pela necessidade. O consumo produz a produção quando esta deve objetivar um produto que atenda a uma necessidade específica. Assim, a sua produção enquanto produto é concretiza da apenas no ato de consumo. Quando um objeto é incapaz de atender a uma necessidade este não é útil, por conseguinte, também não é produto. Por sua vez, o consumo produz a produção quando determina que o produto deve ser rigorosamente coerente com a necessidade a ser atendida.

Mas a análise dialética também apresenta a própria necessidade como histórica. $\mathrm{O}$ que permite compreender que da necessidade atendida pelo consumo surge a possibilidade de uma nova necessidade. Assim, o consumo produz uma nova

\begin{tabular}{|l|l|l|l|l|} 
Revista Dialectus & Ano 1 & n. 1 & Julho-Dezembro 2012 & p. 83-94 \\
\hline
\end{tabular}


necessidade e, por conseguinte, produz a produção ainda no campo do ideal quando determina a existência ideal do produto que atenderá à nova necessidade, produção subjetiva do produto. Portanto, do consumo surge a atividade teleológica, a qual conduz a ação - as causalidades postas - coerentes para a concretização da finalidade previamente estabelecida pela nova necessidade. Ou seja, no consumo está a origem da nova objetivação, o que significa que o consumo cria a produção.

As relações de múltiplas determinações entre os fenômenos, expostas pelo método dialético, estão expressas quando apontamos que do duplo caráter de determinação do consumo sobre a produção resulta uma relação de tripla determinação da produção em relação ao consumo.

$1^{\circ}$. A produção fornece ao consumo a sua matéria, o seu objeto. Um consumo sem objeto não é consumo; nesse sentido, portanto, a produção cria, produz o consumo. $2^{\circ}$. Mas não unicamente o objeto que a produção dá ao consumo. Dálhe ainda o seu aspecto determinado, o seu caráter, o seu acabamento (finish). Tal como o consumo dá o retoque final a produção, a produção dá-o ao consumo. Em primeiro lugar o objeto não é um objeto geral, mas um objeto determinado, que deve ser consumido de forma determinada, à qual a própria produção deve servir de intermediário. A fome é a fome, mas a fome que se satisfaz com a carne cozinhada, comida com faca e garfo, não é a mesma fome que come a carne crua servindo-se das mãos, das unhas, dos dentes. Por conseguinte, a produção determina não só o objeto do consumo, mas também o modo de consumo, e não só de forma objetiva, mas também subjetiva. Logo, a pro-dução cria o consumidor. $3^{\circ}$. A produção não se limita a fornecer um objeto material à necessidade, fornece ainda uma necessidade ao objeto material. Quando o consumo se liberta da sua grosseria primitiva e perde o seu caráter imediato [...], próprio consumo, enquanto instinto, tem como intermediário o objeto. A necessidade que sente desse objeto é criada pela percepção deste. (MARX, 1983, p. 210).

Da determinação da produção pelo consumo surge a determinação do consumo pela produção. Vimos, anteriormente, que no consumo está a possibilidade histórica de concretização de uma nova necessidade, da qual surge a produção subjetiva do objeto, prévia ideação, que determina a produção do objeto. O movimento dialético está completo quando o produto objetivado permite a objetivação do consumo, portanto, a produção cria o consumo ao fornecer-lhe a sua matéria.

Entretanto, a produção também lhe fornece uma matéria determinada - o produto enquanto objeto subjetivado - que atende a uma necessidade específica. Esse objeto humanizado, que é determinado, determina o seu modo de utilização, o modo consumo. Como explica Leontiev (s.d.) para Marx, o produto é um objeto social no qual está incorporado e fixado um conjunto de operações com conteúdo sócio-histórico. A utilização do objeto pressupõe uma determinada ação prática em seu consumo. Contudo, essa ação prática é efetivada no ato da produção, no conjunto de conteúdos 
que são exteriorizados no objeto pelo homem. Assim, a produção objetiva produz a maneira exata de atender a uma necessidade, trata-se da produção do consumo de maneira objetiva. Mas também determina o modo de realização do indivíduo, sua fruição do ser social ao consumir o objeto; também determina o modo de consumo em sua forma subjetiva.

O consumo determina a produção ao criar uma necessidade que dá origem a um produto particular. Mas o caminho inverso também se realiza quando um produto particular cria uma necessidade. O consumo é criado pelo objeto, ou seja, pela produção - já que o objeto é intermediário do consumo à medida que a percepção do objeto em seu conteúdo sócio-histórico cria no indivíduo uma nova necessidade vinculada diretamente à função útil que o produto é capaz de atender, a necessidade é originada a partir da existência corpórea do produto. Assim, sobre a relação entre produção e consumo, conclui Marx (1983, p. 210):

a produção não cria somente um objeto para o sujeito, mas também um sujeito para o objeto [...] De igual modo o consumo engendra a vocação do produtor, solicitando-lhe a finalidade da produção sob a forma de uma necessidade determinante.

No desenvolvimento da investigação, Marx (1983, p. 211) compreende a relação de identidade entre produção e consumo sobre um triplo aspecto:

\begin{abstract}
$1^{\circ}$ Identidade imediata. A produção é consumo; o consumo é produção. Produção consumidora. Consumo produtivo.

$2^{\circ}$ Ambos surgem como intermediários um do outro; uma é intermediada pelo outro, o que se exprime pela sua interdependência, movimento, movimento que os relaciona entre si e os torna reciprocamente indispensá-veis, embora se conservem exteriores um ao outro.

$3^{\circ} \mathrm{A}$ produção não é apenas imediatamente consumo, nem o consumo produção; igualmente a produção não é apenas um meio para o consumo, nem o consumo um fim para a produção, no sentido em que cada um dá ao outro o seu objeto, a produção o objeto exterior do consumo, o consumo o objeto figurado da produção. De fato, cada um não é apenas imediatamente o outro, nem apenas intermediário do outro: cada um, ao realizar-se, cria o outro; criase sob a forma do outro.
\end{abstract}

Portanto, na relação de identidade entre produção e consumo, produtor e consumidor objetivam-se à medida que personificam o objeto. A relação de identidade está no indivíduo quando consumo e produção possuem em si o conteúdo que oferece forma ao ser social, expressam, portanto, o seu processo de hominização. A objetivação do objeto - que se dá na esfera da produção e do consumo - contém em si o processo de tornar-se homem do homem, sua subjetivação. A relação de identidade entre consumo e produção concretiza-se no ser e, portanto, contém em si um conteúdo ontológico ao determinar a existência do ser social enquanto indivíduo produtor-consumidor. Marx 
(1983, p. 211) confirma a nossa análise ao afirmar que

É o consumo que realiza plenamente o ato da produção ao dar ao produto o seu caráter acabado de produto, ao dissolvê-lo consumindo a forma objetiva independente que ele reveste, ao elevar a destreza, pela necessidade de repetição, a aptidão desenvolvida no primeiro ato da produção; ele não é somente o ato último pelo qual o produto se torna realmente produto, mas o ato pelo qual o produtor se torna também verdadeiramente produtor. Por outro lado, a produção motiva o consumo ao criar o modo determinado do consumo, e originando em seguida o apetite do consumo, a faculdade de consumo sob a forma de necessidade.

A unidade entre consumo e produção engendra a individualidade humana, essa surge como resultado de uma relação de totalidade entre os fundamentos do processo de reprodução, o que nos permite compreender o consumo como meio de objetivação do ser, no qual a capacidade exteriorizada do ser durante a produção retorna ao ser e o determina enquanto indivíduo. O consumo é, pois, o momento de fruição das diversas capacidades humanas, um dos momentos de desenvolvimento da subjetividade, resultado do atendimento das necessidades. A produção também é um momento de fruição do ser, na qual as suas capacidades de produtor são desenvolvidas e por meio do produto, são compartilhadas socialmente. Assim, a relação de identidade entre produção e consumo tem sua síntese na constituição do ser social, no seu processo de reprodução enquanto membro de uma sociabilidade - o que permite a Marx (1987, p. 14) afirmar que produção e consumo são dois momentos de um mesmo processo, já que:

\footnotetext{
Para um indivíduo, produção e consumo manifestam--se como momentos de um mesmo ato. Importa apenas sublinhar que quer se considere a produção e o consumo como atividade de um sujeito ou de numerosos indivíduos, ambos os atos surgem de qualquer modo como momentos de um processo em que a produção é o verdadeiro ponto de partida e portanto também o momento predominante. O consumo enquanto necessidade é um fator interno da atividade produtiva; mas esta é o ponto de partida da realização e, portanto, o seu fator predominante, $\mathrm{o}$ ato em que todo o processo novamente se desenvolve. O indivíduo produz um objeto, e pelo consumo deste regressa a si mesmo, mas o faz enquanto indivíduo produtivo e que reproduz. $\mathrm{O}$ consumo surge assim como um momento da produção.
}

A relação intermediada pela necessidade entre produção e consumo pressupõe uma relação de movimento, um percurso contínuo de ida e volta nos dois momentos do mesmo processo. Esse movimento dialético adquire a forma de uma espiral ao originar mutuamente uma nova produção e um novo consumo, e, consequentemente, um novo ser social. A produção é a exteriorização das capacidades do ser social no objeto, o consumo é consumo da própria capacidade do ser social, a capacidade que retorna a si. No retorno a si mesmo encontra-se um homem transformado, pois a produção do produto e o seu consumo o transformam ao realizar a fruição entre os

\begin{tabular}{|l|l|l|l|l|}
\hline Revista Dialectus & Ano 1 & n. 1 & Julho-Dezembro 2012 & p. 83-94 \\
\hline
\end{tabular}


homens. A transformação do ser se dá ao apreenderem as suas diversas capacidades sociais, efetivando a transformação individual que ao mesmo tempo é coletiva. O ser social é consumidor e produtor, e no seu ser-em-si o movimento ineliminável concretiza o processo de autorreprodução, como uma constante objetivação do novo, o que permite um constante reinventar do ser. A exposição marxiana denuncia o caráter de unidade entre produção e consumo como dois momentos de um mesmo processo. Todavia,

na sociedade a relação entre produtor e o produto, quando este último se considera acabado, é uma relação exterior, e o retorno do produto ao sujeito depende das relações deste com os outros indivíduos. (MARX, 1983, p. 212).

Portanto, produção e consumo como atos efetivados em sociedade não são dois momentos de um processo individual, mas são dois momentos de um processo coletivo o que pressupõe relações sociais por intermédio das quais a produção se completa no consumo. Assim, Marx (1983, p. 212) define que o produtor:

Não se torna imediatamente proprietário. Tanto mais que a imediata
apropriação do produto não é o objetivo do produtor ao produzir em sociedade.
Entre o produtor e os produtos interpõe-se a distribuição, que obedecendo a
leis sociais determina a parte que lhe pertence na totalidade dos produtos,
colocando-se assim entre a produção e o consumo.

A unidade entre produção e consumo - enquanto fenômenos objetivados em momento distintos por diferentes indivíduos na sociedade - é efetivada ao encontrar na distribuição uma mediação necessária. Marx (1983), ao apresentar o fenômeno da distribuição como uma categoria social, submetida às leis sociais gerais sobre as quais estão submetidos também os momentos da produção e do consumo, dá-nos a indicação para compreendermos que a distribuição não é um fenômeno autônomo ou exterior a produção. Mas é justamente determinado pela produção, já que o modo como os indivíduos a organizam carrega em si a forma pela qual organizam a distribuição da riqueza social. Marx (1987) encontra o conteúdo dessa afirmação na história dos homens, ao observarmos a relação de produção estabelecida sob a égide do trabalho escravo e servil que expressa o modo pelo qual os indivíduos participam da produção assim como determina a forma como estes participam da distribuição. Portanto, a forma como os indivíduos participam da produção determina a forma como estes indivíduos participam da distribuição. Desta afirmação deduzimos uma lei social que expressa a unidade entre produção e distribuição, de onde se apreende a relação de determinação do modelo de produção sobre a forma de distribuição da riqueza social. Marx expressa a validade desta lei quando se refere ao trabalho

\begin{tabular}{|l|l|l|l|l|}
\hline Revista Dialectus & Ano 1 & n. 1 & Julho-Dezembro 2012 & p. 83-94 \\
\hline
\end{tabular}


assalariado e confirma a relação da produção enquanto determinante da distribuição ao afirmar que um

indivíduo que participe da produção por meio do trabalho assalariado, participa na repartição dos produtos, resultados da produção, através do salário. A estrutura da distribuição é inteiramente determinada pela estrutura da produção. A própria distribuição é um produto da produção, não só no que diz respeito ao objeto, apenas podendo ser distribuído o resultado da produção, mas também no que diz respeito à forma, determinando o modo preciso de participação na produção as formas particulares da distribuição, isto é, determinando de que forma o produtor participará da produção. (MARX, 1983, p. 213).

A unidade entre produção e distribuição não se resume à relação de determinação da produção sobre a distribuição, já que a distribuição também exerce sobre a produção uma relação de determinação. O conteúdo desse segundo momento da relação entre determinantes expresso na unidade entre produção e distribuição está presente quando refletimos sobre os demais momentos da distribuição, pois essa antes de ser distribuição

\begin{abstract}
dos produtos, ela é: $1^{\circ}$, distribuição dos instrumentos de produção e, $2^{\circ}$, distribuição dos membros da sociedade pelos diferentes gêneros de produção, o que é uma outra determinação da relação anterior. (Subordinação dos indivíduos a relações de produções determinadas.) A distribuição dos produtos é manifestamente o resultado desta distribuição que, incluída no próprio processo de produção, lhe determina a estrutura. (MARX, 1983, p. 214).
\end{abstract}

Assim, a distribuição dos meios de produção e dos indivíduos no processo de produção - a concretização da divisão social do trabalho - efetiva uma estrutura de distribuição que acaba por determinar toda a produção, assim como a parcela destinada aos diversos sujeitos da totalidade da produção, o que determina o indivíduo. Portanto, a distribuição determina não só a produção, mas determina o produtor, ou seja, determina o ser social. Marx (1983, p. 213-214) coloca a questão sobre os seguintes termos:

Em relação ao indivíduo isolado, a distribuição surge naturalmente como uma lei social, que condiciona a sua posição no interior da produção no quadro, da qual ele produz, e que precede portanto a produção. Originariamente, o indivíduo não tem capital nem propriedade fundiária. Logo ao nascer é reduzido ao trabalho assalariado pela distribuição social.

A unidade entre produção e distribuição expressa a sua síntese no processo de constituição do ser social, ao determinar a individualidade do ser e o ser enquanto membro de uma coletividade, o que significa que a individualidade é sempre expressão singular de um coletivo, ou seja, a constituição do ser é um processo de fruição no qual estão expressos os diversos determinantes sociais - entre os quais enfatizamos a produção e a distribuição - que constituem uma síntese no individuo.

Contudo, a determinação do indivíduo é concretizada no processo de distribuição

\begin{tabular}{|l|l|l|l|l|}
\hline Revista Dialectus & Ano 1 & n. 1 & Julho-Dezembro 2012 & p. 83-94 \\
\hline
\end{tabular}


e produção, em que as diferentes parcelas do produto social destinadas aos indivíduos na distribuição, determinada pelas funções exercidas pelos distintos sujeitos sociais no interior da produção, os constituem como diversos e desiguais entre si.

Portanto, a síntese dialética entre produção e distribuição constitui o todo social como uma coletividade partida, uma síntese da particularidade no interior da universalidade, que é a constituição ontológica das classes sociais. A classe social, portanto, configura-se como um coletivo particular que constrói sua unidade a partir de determinações particulares no interior das diversas relações estabelecidas entre produção e distribuição. Assim, o coletivo se estabelece enquanto classe social ao ter, enquanto determinantes para sua reprodução coletiva nexos causais similares postos pelo modo de distribuição dos meios de produção, e a consequente distribuição dos indivíduos no processo de produção.

A continuidade da exposição marxiana denuncia que o processo de distribuição da riqueza é concretizado quando o produto chega ao indivíduo, o que apenas se efetiva por meio da mediação da relação de troca, já que a troca surge como a continuação do processo de divisão da riqueza, mas a partir das necessidades individuais. Assim sendo, a indivíduo; a troca determina os produtos que cada indivíduo reclama como parte que lhe foi designada pela distribuição. (MARX, 1983, p. 207).

A distribuição enquanto distribuição social da riqueza surge na sociedade como um todo, enquanto a troca tem por origem o indivíduo, o ser social em suas necessidades singulares. Assim como a "própria circulação é apenas um momento determinado da troca, ou a troca considerada em sua totalidade." (MARX, 1983, p. 214). Portanto, a troca é o segundo momento do processo de distribuição, momento de repartição individual da riqueza coletiva, que por sua vez também determina a existência das classes sociais.

Logo, produção e distribuição são mediadas pelas relações de troca. Chegamos, assim, a necessidade de expor o momento último da relação geral de reprodução, a relação entre produção e troca. Marx (1983, p. 216) expõe essa relação ao afirmar que à medida que

a troca não é mais do que um fator servindo de intermediário entre a produção e a distribuição que ela determina tal como o consumo, na medida, por outro lado, em que este último surge como um dos fatores da produção - a troca constitui manifestamente um momento da produção. 
Portanto, Marx (1983) expressa a relação de unidade entre troca e produção, à medida que a primeira é expressão da necessidade do ser social, o que determina diretamente o processo de produção ao apresentar a alternativa do que exatamente produzir. Expõe, assim, a relação de determinação entre produção e troca como dois momentos do processo social de reprodução, dois momentos de uma totalidade, que constroem a sua unidade em uma relação de determinação sobre três momentos distintos:

\begin{abstract}
Em primeiro lugar; é evidente que a troca de atividades e de capacidade que tem lugar na própria produção, faz diretamente parte desta, constituindo um dos seus elementos essenciais. Em segundo lugar, isto é verdade para a troca de produtos, na medida em que esta troca é o instrumento que fornece o produto acabado, destinado ao consumo imediato. Nesse sentido, a própria troca é um ato incluído na produção. Em terceiro lugar, a troca (exchange) entre negociantes (dealers) é, pela sua organização, inteiramente determinada pela produção, ao mesmo tempo que atividade produtiva. A troca só aparece como independente ao lado da produção, como indiferente em presença desta, no último estágio em que o produto é trocado para ser imediatamente consumido (MARX, 1983, p. 217).
\end{abstract}

Da relação entre determinante e determinado estabelecida na unidade entre produção e troca, Marx (1983, p. 217) deduz leis gerais constituídas socialmente que dão forma e conteúdo às relações sociais de troca geral:

$1^{\circ}$, não há troca sem divisão do trabalho, quer esta seja natural quer umresultado histórico; $2^{\circ}$, a troca privada supõe a produção privada; $3^{\circ}$, a intensidade da troca, tal como a sua extensão e o seu modo, são determinados pelo desenvolvimento e pela estrutura da produção.

Então, um modo de produção evoluído produz uma estrutura de circulação de toda a produção social, ou seja, trata-se de constituir um modelo de circulação coerente com as capacidades produtivas. Assim como a produção privada constitui a troca privada o que em conjunto com o modelo de divisão de trabalho historicamente constituído dá forma a um modelo de reprodução, em que diferentes classes sociais exercem posições distintas e antagônicas no processo de produção, acabam por ocupar também posições desiguais na relação de circulação da produção, o que significa a apropriação desigual dos bens produzidos.

Do exposto, podemos concluir que, no seio desse processo de reprodução histórica, encontramos os nexos causais que constituem as classes sociais como uma determinação coletiva do ser social, como uma construção do ser social em sua existência individual e coletiva que se efetiva nas determinações constituídas na unidade orgânica expressa nos fundamentos do processo de reprodução social. Marx, sobre essa relação de unidade entre os quatro fatores expressa:

\begin{tabular}{|l|l|l|l|l|}
\hline Revista Dialectus & Ano 1 & n. 1 & Julho-Dezembro 2012 & p. 83-94 \\
\hline
\end{tabular}




\begin{abstract}
Não chegamos à conclusão de que a produção, a distribuição, a troca e o consumo são idênticos, mas que são antes elementos de uma totalidade, diferenciações no interior de uma unidade. A produção ultrapassa também o seu próprio quadro de determinação antitética de si mesma, tal como os outros momentos. É a partir dela que o processo recomeça sem cessar. É evidente que a troca e o consumo não podem prevalecer sobre ela. $\mathrm{O}$ mesmo acontece com a distribuição enquanto distribuição dos produtos. Mas, enquanto distribuição dos agentes de produção a distribuição é um momento da produção. Uma produção determinada determina portanto um consumo, uma distribuição, uma troca determinados, regulando igualmente as relações recíprocas determinadas desses diferentes momentos. A bem dizer a produção, na sua forma exclusiva é também, por seu lado, determinada pelos outros fatores. Quando o mercado, ou seja, a esfera da troca, por exemplo, se desenvolve, cresce o volume da produção, operando-se nela uma divisão mais profunda. Uma transformação da distribuição provoca uma transformação da produção; é o caso da concentração do capital, da repartição diferente da população entre a cidade e o campo, etc. Finalmente, as necessidades inerentes ao consumo determinam a produção. Há reciprocidade de ação entre os diferentes momentos. O que acontece com qualquer totalidade orgânica. (MARX, 1983, p. 217).
\end{abstract}

Portanto, os quatro fatores compõem uma unidade insuperável, de unidade na diferença, em que o conteúdo de cada fator é distinto dos demais, mas o seu conteúdo pode ser apreendido somente em sua essência, em sua relação de totalidade com os demais fatores. A unidade se constitui no próprio movimento dialético estabelecido entre os quatro elementos, no qual a produção é ao mesmo tempo síntese e nova tese, já que o constante movimento em espiral, que perpassa os diferentes momentos produção, distribuição, troca, consumo, produção - sempre dá origem a um novo movimento. Assim, o movimento dialético constitui uma totalidade orgânica a exteriorizar leis próprias que regem o movimento da totalidade social - que constituem o ser social enquanto consumidor e produtor em uma apreensão do fenômeno, que adquire na sociedade capitalista, um conteúdo particular ao formar o ser social em sua existência fragmentada em classes sociais com conteúdo historicamente determinado.

\title{
Referências Bibliográficas
}

LEONTIEV, Alexis. O desenvolvimento do psiquismo. São Paulo: Editora Moraes, [s.d.].

MARX, Karl. Contribuição à critica da economia política. 2.ed. Tradução Maria Helena Barreiro Alves. São Paulo: Martins Fontes, 1983.

Elementos fundamentales para la crítica de la economía política (Grundrisse) 1857 - 1858. 15.ed. México: Siglo Vein-tiuno Editores, 1987. 